\title{
An Examination of Berman's Negative Deformation Tendencies on Persian Translation of Tess of the d'Urbervilles Novel
}

Fahimeh Vamenani, Moslem Sadeghi*

Bandar Abbas Islamic Azad University, Bandar Abbas, Iran

Corresponding Author: Moslem Sadeghi, E-mail: Sadeghim1354@yahoo.com

\section{ARTICLE INFO}

Article history

Received: March 17, 2018

Accepted: May 23, 2018

Published: September 01, 2018

Volume: 7 Issue: 5

Advance access: July 2018

Conflicts of interest: None

Funding: None

\begin{abstract}
The primary purpose of this study was to examine the frequency of deforming tendencies on Persian translation of Hardy's Tess of the d'Urbervilles based on Berman's model. Moreover, the study set out to find out how words have been changed from the source language to fit the target language by adopting deforming tendencies. To achieve the aims of study, the researchers relied on content or document analysis as a qualitative type of study to analyze the strategies which were used in the translation of Tess of the d'Urbervilles novel from English to Persian. The data came from a sample of 300 sentences which were randomly selected from the novel translated into the Persian language by Mina Sarabi.The trustworthiness of the research findings was met through inter-rater agreement and it was reported 0.94 . The results indicated that Persian translation of the work suffered from lexical mismatches, destruction of rhythm and destruction of vernacular networks, although destruction of rhythms and destruction of vernacular networks were among the most frequently used deformation tendencies. The findings also revealed that the translation has in one way or another maintained the genre and social stance of the author. Overall, it appears that Berman offers a model which is too severe on keeping the form and syntax of the source text in the Persian translation of Hardy's Tess of the d'Urbervilles.
\end{abstract}

Key words: Berman's Model, Content Analysis, Deforming Tendencies, Persian Language, Tess Of The D'urbervilles

\section{INTRODUCTION}

Translation studies is an academic research area that has massively expanded over the years. Translation was formerly studied as a language-learning methodology or as a part of comparative literature, translation 'workshop' and contrastive linguistics courses. The interrelated branches of theoretical, descriptive and applied translation studies initially structured research. Over the time the "inter-disciplinary and specialization of the subject have become more evident and theories and models have continued to be imported from other disciplines but also forged from within translation studies itself" (Munday, 2016, p.27). Catford (1965) drawing on linguistic theory and defines translation as follows: "Translation is an operation performed on languages: a process of substituting a text in one language for a text in another. Clearly, then, any theory of translation must draw upon a theory of language, i.e. a general linguistic theory" (p.1). Nida views a scientific approach into the subject of translation and argues that translation is a scientific activity which is "the transference of a message from one language to another is a valid subject for scientific description" (Nida, 1964, p.3). In the same line of thought, Newmark (2001) believes in the importance of text and defines translation as "a craft consisting in the attempt to replace a written message and/or statement in one language by the same message and/ or statement in another language" (p.7). Simon (2006) in her definition of translation with a focus on cultural elements argues that some translations are "maneuvers that represent shifts in cultural history or which consciously exploit the limit, raising the temperature of cultural exchange" (p.16).

Among different approaches, Berman has a philosophical approach to translation criticism. He (1995) believes that there may be many different methods for translation criticism as there are many translation theories; therefore, every translator according to the specific objectives can define a translation project. For Berman, criticism has positive and negative implications: it is in essence positive and for him, purely negative criticism is not a real one. He states that the very expression translation criticism may cause misunderstandings since it appears to refer only to the negative evaluation of translations. Since the Enlightenment era, criticism has always dealt with negatives, regardless of its object, but Berman emphasizes that "we should not forget that the other face of the negative is the positive" $(1995$, p. 1$)$. He adds that the basis of the evaluation is meant to remain neutral and avoid being dogmatic by a certain respect for the original (ethical aspect) and the poetic nature of a translation in the 
textual work of a translator. Therefore, from Berman's point of view, if literary criticism is an essential part of the life of literary works, then translation criticism must consider in the same way as seriously as literary criticism.

Translation analysis is a series of chains between translation study and translation practice (Newmak, 1992). In this way, Berman (2000) deplores the general tendency to negate the foreign translation by the translation strategy of naturalization which would be equated with Venuti's (2012) later domestication. Then, the properly ethical purpose of translation is receiving foreign as foreign, which would seem to have influenced Venuti's (2012) foreignizing translation strategy, however, there is generally a "system of textual deformation "in - target texts- (TTs) that prevents the foreign through which is termed negative analytic" (Berman, 2000, p. 277). The Last but not the least point is that story books and novels can be regarded as a means to express one nation's feelings and attitudes, and translation is regarded as a bridge through which different cultures can get closer together (Niknasab \& Pishbin, 2011).

Literary works are deemed as the optimal outcome of literature however they pose significant problem for translators who feel the pressure of producing another masterpiece in another language. Some scholars such as Berman and Venuti are skeptical about the success of this task and argue that the translation of literary works are liable to naturalization and the adoption of what Berman calls deforming tendencies are very high in this case. Accordingly this study aims at testing Berman's deforming tendencies model in the translation of Hardy's Tess of the d'Urbervilles with a focus on finding the frequency of applied strategies on the part of the translator. To this end the twelve deforming forces or tendencies are analyzed. These tendencies are as follow: rationalization, clarification, expansion, ennoblement, qualitative impoverishment, quantitative impoverishment, destruction of rhythms, destruction of underlying networks of signification, destruction of linguistic patterning, destruction of vernacular networks or their exoticization, destruction of expressions and idioms, and effacement of the superimposition of languages. The main reasons for conducting the present research were that less critical attention has been devoted to the negative analytic theory of translation. Since there have been a lot of translated works regarding the novels and literary masterpieces from English to Persian language, there is a kind of avoidance among translators to the matter of translation from critical perspective, particularly in the translation of Tess of the d'Urbervilles. Therefore, all these good motivations persuaded me to conduct this research. It also seemed essential to elaborate a precise and scholarly method for translation criticism in order to produce healthy and objective critiques for translated texts as it would be indispensable for the students, translators and critics interested in raising the quality of literary translation. The purpose of this research was to assess the model of deforming tendencies presented by Berman on Persian translation of Hardy's Tess of the d'Urbervilles and finding out whether there is such a deforming tendency in the translation of this literary work into Persian or not. Therefore, the present study was an attempt to answer the following questions: (1) what are the most frequent deforming tendencies in Persian translation of Hardy's Tess of the d'Urbervilles based on Berman's model?; and (2) how do words experience changes from the source language (English) to fit the target language (Persian) by adopting deforming tendencies?

\section{LITERATURE REVIEW}

The untranslatability of literary works has always been a focal point in translation studies. How literary works should be translated, and what factors should be considered in its translation were the matters of consideration for researchers. Whereas some scholars contend that literary works are translatable, others support the idea of untranslatability of literary works. What is meant by translatability is the possibility of translating a text linguistically and culturally from one language into the other (Almasaeid, 2013). Because of its special features, as well as its aesthetic and expressive values, literary translation is more difficult than the translation of other types of texts. The aesthetic function in a literary work emphasizes the diction of work, its figurative language, metaphors, etc. The expressive function emphasizes the writer's thought or process of thought, emotion, etc. The translator's prophecy is transferring these specific values to the target language (Hariyanto, 2003). Since the process of translation is almost always possible, it may for different reasons not to have the same influence as the source text (ST) or original (Newmark, 2001). One of the reasons might be the fact that deviation in the target language usually differs from that of the original. Therefore, the proper translations and finding correct equivalents have a great importance. This importance might be directed to achieve intended goals of the writer, provoke the same impact from the target audiences, and preserve the cultural and local coloring of the original text. Hariyanto (2003) asserted that translation of poetry has features special to its own in comparison to other genres of literature. A poem achieves its beauty not only with the words choice and its figurative language as in novels, but also with the creation of rhythm, meter, specific expressions and structures that have an important effect on achieving the beauty.

\section{Berman's Deforming Tendencies}

The twelve deforming tendencies proposed by Berman are: (1) rationalization: this tendency affects syntactic structures (e.g., sentence structure, punctuation, order); (2) clarification: it makes explicit and clear what the authors do not wish to be clear in the ST; (3) expansion: any translation is longer than ST, but this expansion is unacceptable. These additions occur over-translation which add nothing but reduce the clarity of the work voice; (4) ennoblement: it refers to the rewriting of the original text in a more elegant style. It means that using elegant style in translation destructs the structure and rhetoric of the ST; (5) qualitative impoverishment: it refers to replacing the expressions and words with their TT equivalents that shortcoming their richness; (6) quantitative impoverishment: it is the attrition of lexical variation in the process of translation when the translator replaces var- 
ious synonyms by one word; (7) destruction of rhythms: it means that if word orders and punctuations are deformed, the rhythms of the text will be destroyed; (8) destruction of underlying networks of signification: words can impact on the sense and underlying network of the text even though they may not have any significant meaning; (9) destruction of linguistic patterning: different techniques of translation, i.e. expansion, clarification and rationalization which are used by translators destroy the constructions and patterning of the original text even though the target texts are linguistically homogenous, there are lack of coherency in meaning because the systemacity of the original texts are destroyed; (10) destruction of vernacular networks or their exoticization: this deformation relates to the matter of local speech. There is an attrition or loss when source language slangs or vernacular replaced by target language vernaculars and follow its linguistic patterning; (11) destruction of expressions and idioms: in Berman's view replacing the proverbs and idioms of SL by their equivalents in TL is a kind of destruction of the discourse of the foreign work; and (12) effacement of the superimposition of languages: it refers to the omission or deletion of any traces of different forms of languages that co-exist in ST in translation (as cited in Venuti, 2012). Subsequently, Venuti's (2012) foreignizing is influenced by the translation strategies suggested by Berman whose definition of the ethical aim of translation act receives the foreign as foreign. Under this definition, text deformation system in TTs, twelve deforming tendencies are suggested that prevent the foreignness of the text to keep in translation. Negative analytic is the term which Berman employed to investigate these deforming tendencies.

\section{Studies on the Translation Feasibility of Literary Works}

Translation studies have developed in a variety of directions and among them are the study of translational techniques. Pavlušová (2014) examined the classification of translation techniques and presents a newly discovered sub-type of naturalization - reverse naturalization. The supporting theory was based on the classification of translation techniques by Vinay and Darbelnet. In another study with a focus on explicitation, Murtisari (2016) demonstrated that while explicitation is a complex notion, many studies of it as a phenomenon fail to provide an adequate explanation of it as a concept. It was reported that the lack of attention to the conceptual issue has often led to methodological choices which limit the validity of the study claims or even nullify them. In a study conducted by Tezcan (2015) which aimed at showing the applicability of Berman's criteria to various text types found in the collection of short stories that there is some loss involving rationalization linked to semantics but no loss involving rationalization and punctuation. There is slight loss involving clarification, which was only applied after consideration was given to Venuti's (1995) theory of domestication to assist the target audience's reception. However, most clarification appears as annotation outside the primary text, thus minimizing deformation, and there is no clarification involving textual interpretation. Some qualitative impoverishment does occur, once again due to domestication that helps to retain equivalent levels of presupposition. There is some idiomatic substitution, but since compensation has been applied, idiomatic loss is once again tied to domestication. Quantitative impoverishment is closely linked to proximity and context but does not emerge as a key factor, while the substitution of vernacular networks only applies to the representation of emphasis.

In Iran several researchers have considered the feasibility of translation of the literary works. For instance, Dastjerdi, Hakimshafaaii and Jannesaari (2008) found that if it is said that poetry is translatable, it does not mean that each aspect of poetry can be translated. Since language patterns are different and some patterns of every language cannot be imitated in another language, close translation of the original is not an impossible ambition because the past translations in the realm of poetry showed ideal results in cross-cultural renderings of great poems of one language to others. Niknasab and Pishbin (2011) focused on presenting a textual and extra textual analysis of a piece of poetry by Sohrab Sepehry. They found that the translator has been successful in the textual level to some degree and that the translated poem would not create the same response and effect as evoked by the original text in the audience and the translated version led to vagueness. Almost all literary devices were translated literally. In another study conducted by Sharifabad, Yaqubi and Mahadi (2013), the results revealed that the translators tended to domesticate the phrasal verbs in news rather than to foreignize them. They also reported that phrasal verbs were mainly idiomatic phenomena and were consequently culture-specific. Ultimately, they claimed that domestication strategy could be more applicable to rendering such phenomena, as domestication strategy focused more on the reader and target language text. Finally, Jafari and Kariminia (2015) investigated the deviation in translation of poetry based on Berman's (1995) model of text deformation system. The findings revealed that rationalization, destruction of rhythm, destruction of linguistic patterning, destruction of underlying network of signification, and expansion were the most frequent items among the twelve deforming items. They concluded that there were deviations, especially syntactic deviation of poetry translation was occurred based on Berman's model.

The debate on whether to use domestication or foreignization has attracted the attention of translation theorists for a long time. Although Venuti advocates foreignizing translation, he is also aware of some of its contradictions, namely that it is a subjective and relative term that still involves some domestication because it translates an ST for a target culture and depends on dominant target-culture values to become visible when it departs from them. Newmark (2001) says that a translation is normally written and intended for a target language reader - even if the source language text was written for no reader at all. He adds that the translator has to assist his reader. In other words it is usually more important for him to make or indicate the sense of a passage than to funk the issue by rendering it, correctly. The study of domestication and foreignization strategies in literary translation can provide valuable insights as far as it can determine the translation tendencies among Iranian translators as a method of translation. 


\section{METHOD}

The present study benefited from content or document analysis as a type of qualitative approach of research. Like other types of qualitative approach, content or document analysis applied to written or visual materials for the purpose of identifying specified characteristics of the material. The analyzed materials can be "textbooks, newspapers, web pages, speeches, television programs, advertisements, musical compositions, or any of a host of other types of documents" (Ary, Jacobs Sorensen; \& Walker, 2014, p.488). This is in line with Magilvy and Thomas (2009) who believed that to analyze the strategies and solutions used by the translator, content or document analysis is an appropriate method for describing the qualitative data. Ary et al. (2014), note that content analysis is widely used in education research in the form of identifying propaganda, bias or prejudice in textbooks. For analyzing and comparing the collected data from the SL and their equivalent to the TL in the present study, the researchers adopted content or document analysis as an appropriate method of the research.

Nevalainen (2004) clearly points out that the following step-by-step approach was adopted to collect the data: (1) The first stage consisted in reading the novel in its original (i.e., English) version several times in order to gain familiarity with the storyline, characters, relationships between the scenes in a word, with the general context in which together with other elements, the extra-linguistic cultural references (ECRs) were used; (2) The next step consisted in identifying still in the original version, the translated parts likely to present from a translational point of view, potential problems of cultural transfer into the target context(s) considered. This process of identification was inevitably subjective due to the inconstant nature of ECRs. Because of this the absence of formal corpus excluded a quantitative study but not a qualitative analysis based on the contextualization of examples. The potential problems were identified. At this stage, an effort was made to record as much contextual information as possible. A similar approach was taken with the corresponding version translated into Persian. In order to uncover the strategies used by the translator for each of the problems identified in the previous stage the recording of contextual information related to these strategies solutions was crucial. It consisted mainly of the co-text (verbal component) but also of the other semiotic codes if any were modified or added through the process of translation. Differences in translation units were taken into account. For example, a single term in English was sometimes rendered by several words in Persian or vice versa (e.g., a paraphrase), or the meaning of a gesture was made explicit verbally in the Persian version, or the non-ECR in English has been rendered as an ECR in Persian. Moreover, examples of compensation (e.g., compensation through other semiotic codes, or implemented in another scene) were also recorded. The analysis is therefore inherently qualitative since the subjective and relative nature of the translation as it precludes a quantitative study involving an exact number of cultural references, and statistics of the translation procedures used. Drawing on the two renowned categories of foreignization and domesti- cation (Venuti, 1995), Berman's "negative analytic" theory of translation was used as the basis for the analysis of the translated text. The data included a sample of 300 sentences which were randomly selected from the novel translated into the Persian language by Mina Sarabi.

For conducting the aforementioned stages, descriptions of specific criteria used for coding of specific examples of the Persian translation was done. In analyzing the gathered data, the researcher kept track three stages like other type of qualitative approach. These stages include: familiarizing and organizing the data, coding and reducing the data, and interpreting and representing the data for analyzing the gathered data in the present study. In the first stage, the gathered data were broken into pieces and labeled into core concepts. Then, connection between the subcategories and main categories was made. Finally, the gathered data under sub and main categories were reorganized under the deforming tendencies of Berman's model. Emphasis was placed on textual effects rather than impact on the audience as this would have required research of a completely different nature (such as an empirical study with a pool of viewers). In order to guarantee the trustworthiness or dependability of the data, the researchers adopted inter-rater agreement. The collected data were coded and labeled by one of the researcher of the current study. Then, the coded data were analyzed by the other researcher as an inter-rater. Finally, by comparing two sets of analyzed data, it was revealed that there were 0.94 similarities of the codes and labels by the two raters.

\section{RESULTS AND DISCUSSION}

\section{Results}

The analysis of the data revealed that all types of deforming tendencies, although with different frequencies, were observed in the translation of the novel. In the following, the evidence for each of twelve deforming tendencies will be presented and discussed one by one.

\section{Rationalization}

According to Berman, rationalization tendency affects syntactic structures (e.g., sentence structure, punctuation, order, even tendency to generalization and translation of verbs by noun forms). Regarding the rationalization tendency, in 286 sentences change of word order was observed. The prevalence of this observation could be highly attributed to the difference between Persian and English in their word orders. However, if we consider this tendency as changing the sentences in a specific order which results in certain shifts in meaning, there were only 10 cases of rationalization $(3.3 \%)$ tendency. An example for rationalization as a deforming tendency is:

ST (source text): The young girls formed, "indeed", the majority of the band

TT (target text): در واقع" دختران جوان بِرشمارتر بودن "

In this example the location of the word "indeed" in the middle of the sentence emphasizes the fact that the girls were really a lot of girls. In fact, in the ST the location of the 
word "indeed" makes it synonymous with really; however, the translator has not taken it into account.

\section{Clarification}

This refers to a situation in which the translator makes it explicit and clear what the authors do not wish to be clear in the ST. Berman maintains that this tendency is undeniable in the process of translation. It was observed in 28 sentences $(9.3 \%)$ and it caused the manifestation of the untold. An evidence for clarification is as follow:

ST: The parson rode a step or two nearer.

TT: كثيش يكى دو كام به او نزديك شد و "كَت

The word "تففگ" in the TT is what Berman refers to as the manifestation of untold. Indeed, the translator has added some words into the target text in order to make it more understandable to the reader.

\section{Expansion}

According to Berman, rationalizing and clarifying require expansion. He believes that any translation is longer than ST, but this expansion is unacceptable. These additions occur over-translation which add nothing but reduce the clarity of the work voice. This kind of tendency was one of the most frequent ones in the corpus of this study; indeed, there were 169 cases $(56.33 \%)$ of expansion in the corpus. Although this tendency may rationalize or clarify a translation, it might diminish the voice of the ST. An example for expansion is presented as follow:

ST: Then what might your meaning be in calling me "Sir John" these different times, when I be plain Jack Durbeyfield "the haggler"?

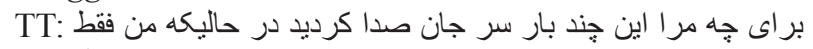

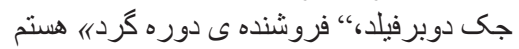

In this example, the translator has expanded the target text in order to make the target text reader understand the translation better. This expansion may render the text more "clear" but they actually obscure its own mode of clarity (Venuti, 2012). Berman (1995) believes that this clarification diminishes the foreignness of the target text.

\section{Ennoblement}

In the corpus of the present study, there were cases of deformation tendency which were resulted from the translator's inclination for rewriting of the original text in a more elegant style. Employing elegant style in translation destructs the structure and rhetoric of the ST. The analysis of the corpus indicated that there were 14 cases $(4.6 \%)$ of ennoblement. One of the most obvious examples of ennoblement is presented below as:

ST: The banded ones were all "dressed in white" gowns TT: اعضاى كروه "سفيد يوش" شده بودند "dited

While the phrase "dressed in white" is used in everyday English (not literary), the Persian translator has opted for the literary term " سفيد يوش شدن" as the equivalent for "dressed in white". In fact, in every day conversation in Persian, one can hardly hear this phrase. It seems as if the translator has tried to produce "elegant" sentences, while utilizing the source text as raw material (Venuti, 2012).

\section{Qualitative impoverishment}

This deformation tendency occurs when the translator replaces the expressions and words with their TT equivalents that shortcoming their richness. It was observed in 51 sentences $(17 \%)$ of the corpus. An instance of qualitative impoverishment is presented below.

ST: but her mobile peony mouth and large "innocent" eyes added eloquence to color and "shape".

اما لبهاى خوش تركيب، كوشتالو و" بى آلايش" زيبايش به شادابى:TT

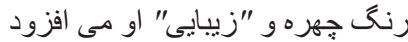

In this case, the word "innocent" has been translated as " in the target text. Similarly, the word "shape" has been translated asزيبيیى". Neither of the two TT words can completely signify the source text words. Indeed, the word "بیى آلايش"refers to anything which is simple and without decoration, with a positive connotation. On the other hand, the word "innocent" refers to something which is not involving evil intent or motive; it refers to having or showing the simplicity or naiveté of an unworldly person. As with the word "shape", it mainly refers to the body and from or something; however, the selected translation, زييايى, is mainly used for the appearance of something.

\section{Quantitative impoverishment}

Regarding the quantitative impoverishment in the corpus of this study, it seems that the translator had sometimes replaced various synonyms by just one word. This point results in lexical loss within the translation. There were 37 cases $(12.3 \%)$ of quantitative impoverishment in the corpus of the present study. An evidence for this deformation tendency is as follow.

ST: She was a fine and "handsome" girl.

TT: او دخترى ظريف و "زيبا" بود

The analysis of the data revealed that more than five different lexical items from the source text were translated into the target text as “زيبا'” "زيبايیى". The main lexical items which were translated as "زيبيى" were: shape, beautiful, handsome, mesmerizing, and brilliant.

\section{Destruction of rhythms}

In Berman's view, the rhythms of the text would be destroyed if word orders and punctuation were deformed. Indeed, the deforming translation can considerably impact on the rhythm (e.g., through an arbitrary revision of the punctuation). In the corpus of this study, there were 98 cases $(32.6 \%)$ of the destruction of rhythms. A case of the destruction of rhythms is presented below.

ST: She wore a red ribbon in her hair.

TT: روبان سرخى داشت، به كيسو انش بسته بود.

In the above instance, there is a rhythmic intonation between the words of the source text. However, the translation of Hardy's novel has destroyed the distinguishing rhythm: 
while the original includes only one sentence, the translation uses two different sentences.

\section{Destruction of underlying networks of signification}

Words can impact on the sense and underlying network of the text even though they may not have any significant meaning The literary work contains a hidden dimension, an underlying text, where certain signifiers correspond and link up, forming all sorts of networks beneath the surface of the text itself. In the corpus of this study 11 cases $(3.6 \%)$ of the violation of the underlying networks of signification were observed. Some main networks of signification were church, religion, and bible jargons. After long intervals certain words from a specific jargon may recur, certain kinds of substantives constitute a particular network, whether through their resemblance or their aim, and their aspect. Indeed, while there were many references to religion and bible expression in the source text, the translator selectively linked them to the related jargons in the target text. Indeed, the translator destroyed the subtext that carries the network of word-obsessions.

ST: On an evening in "the latter part of May" a middle-aged man "was walking homeward" from Shaston to the village of Marlott, in the adjoining Vale of Blakemore, or Blackmoor.

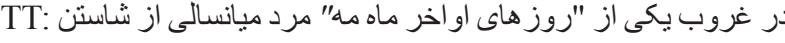

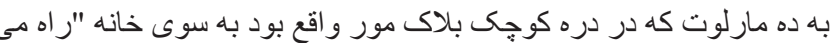

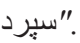

The translator has destructed the underlying network of the meaning both in ST and TT. Month of "May", which is the fifth month of Christian calendar, belongs to the season of spring. It coincides with the meaning of freshness and fertility of the earth that all flowers blossom and the mother of earth is ready for reproduction. In fact, when an English reader reads the word "May", it associates the meaning of fertility and production in his/her mind. In the contrary, within the TT translation, the translator just has sufficed to the word " ماه مه " which has no network of meaning for Persian reader, to whom "مروردين و ارديبهشت" "ماه" "are the months of reproduction and blossoming of the flowers and plants in the Solar calendar. Therefore, through the breaking of the underlying network of signification, the translator has destroyed the freshness and vitality of this month "May" in ST and has never conveyed the meaning of liveliness and robustness in TT. Consequently, the suitable translation of the excerpt must be rendered as "روز هاى او اخر ارديبهشت ماهي". Through this new rendering, the TT reader would be mentally engaged with the aesthetic aspects of this month and would thoroughly perceive the meaning of this month and its vitality and vividness.

\section{Destruction of linguistic patterning}

From Berman perspective, different techniques of translation, i.e. expansion, clarification and rationalization which are used by translators destroy the constructions and patterning of the original text even though the target texts are linguistically homogenous, there are lack of coherency in meaning because the systemacity of the original texts are destroyed. There were 71 cases $(23.6 \%)$ of the destruction of linguistic patterns in the corpus of this study. An instance of this deforming tendency is as follow:

ST: There's more in it than you know of, "perhaps".

TT: "شايد“" ، بيشتر از اينها كه تو فكر مى كنى اين كار فايده داشته، باشد.

In the above example, the linguistic structure of the source text was destroyed. This point is more deeply felt when we know that in English the exclamation "perhaps" and the adverb "perhaps" can be used in the both beginning and the end of a sentences. Then, the author of the novel could have used the two expressions, if there was a need to, at the beginning of sentences. This is what the translator has done! A carefully conducted textual analysis of an original and its translation demonstrates that the writing-of-the-translation and the-discourse-of-the-translation is a systematic.

\section{Destruction of vernacular networks or exoticization}

There is an attrition or loss when source language slangs or vernacular replaced by target language vernaculars and follow its linguistic patterning. This was one of the most frequent deforming tendencies in the corpus of this study. There were 103 cases $(34.3 \%)$ of vernacular or source text slangs replaced by target text vernaculars which follow its linguistic patterning. In the following, an evidence for this deforming tendency is presented.

ST: "I've-got-a-great-family-vault-at-Kingsbere".

TT: “"من دارم در كينكز بر مقبره خانو ادگى بزرخى"

In the above example, the original text has been used vernacular which has been replaced by target language vernacular.

\section{Destruction of expressions and idioms}

While the source text was replete with proverbs, expressions and idioms, the TT was less idiomatic. There were 66 cases $(22 \%)$ of the destruction of expressions and idioms in the target text. In Berman's view replacing the proverbs and idioms of SL by their equivalents in TL is a kind of destruction of the discourse of the foreign work. Below, we can see this deformation tendency.

ST: Joan Durbeyfield must mind that she don' $t$ "get green malt in floor".

TT: جان بايد مر اقب باشه تا قبل از ازدو اج رسمى حاملكى اتفاق نبفته.

In this example, the idiom has been destroyed. So, there is a kind of the destruction of expressions and idioms is occurred in the TT.

\section{Effacement of the superimposition of languages}

Berman (2000) uses this term to refer to the omission or deletion of any traces of different forms of languages that co-exist in ST in translation. Regarding this definition, 15 instances $(5 \%)$ were observed in the corpus of this study. In the following, an evidence for this deforming tendency is presented. 
ST: The pedestrian, after "another" pace or two, halted, and turned round.

TT: مرد يُ از "يكى دو كام"درنگ كرد و بركثَت.

The word "another" is a lexical item which could be translated into the target text. However, it has been omitted.

Therefore by considering all of the above mentioned examples for each of the twelve deformation tendencies, the researchers concluded that these deformations were occurred when the translator translated the text from SL, i.e. English language to the TL, i.e. Persian language. Table 1 provides a summary of the frequency and percentage of each deformation tendency.

Figure 1 illustrates a graphic representation of the frequency and percentage related to each deformation tendency based on Berman's model.

To put it in a nutshell, the research tried to extract particular instances from the text and related them to the main concepts of Berman's deforming model. So, each relevant terms, phrases and sentences was selected and classified under their categories and subcategories. In this way, the research took into consideration the meaning and structure of words, phrases and sentences in both the SL and TL and compared them together. Finally, the representation of the frequency and percentage for twelve deformation tendencies of Berman's model were presented by the table and graph.

\section{Discussion}

The primary purpose of this study was to investigate the frequency of deforming tendencies in the translation of Hardy's Tess of the d'Urbervilles under Berman's model. Moreover, the study was set out to find out how words have been changed from the source language to fit the target language by adopting deforming tendencies. This purpose was met through specifying the most frequent deformation tendencies. Overall analysis of the data revealed that the expansion, destruction of rhythms, and destruction of vernacular networks were among the most frequently used deformation tendencies. Moreover, the analysis of the data revealed that rationalization, destruction of underlying networks of signification, and ennoblement were the least frequent deformation tendencies. Findings of the present study revealed syntactical deviations that occurred in structure, punctuation, rhythms, etc. in the translation of prose. It was also revealed that meaning deviation occurred less in the translation of prose based on this model. In fact, it seems that Berman offers a model which is too severe on keeping the form and syntax of the source text in translation. Some of these findings are in line with the previous studies such as Dastjerdi, et.al. (2008) Pavlušová (2014), and Jafari and Karimnia (2015). For instance Jafari and Karimnia (2015) set out to investigate deviation in translation of Molana poetry based on Berman's (1985) model. Similar to the present study, their findings revealed that expansion is the most frequent items among the twelve deforming items. In the same vein, they observed that destruction of rhythms is one of the most frequent deformation items. However, there are some contradictions between the two studies. For instance, while rationalization was the least frequent deformation tendency in the present study, it

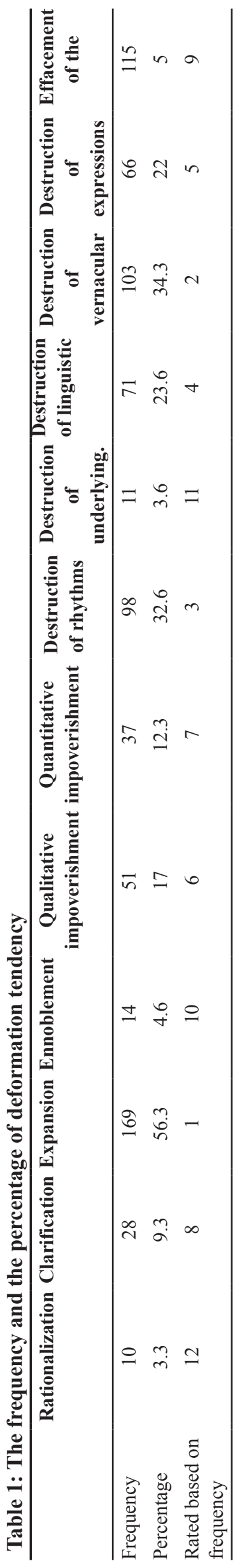




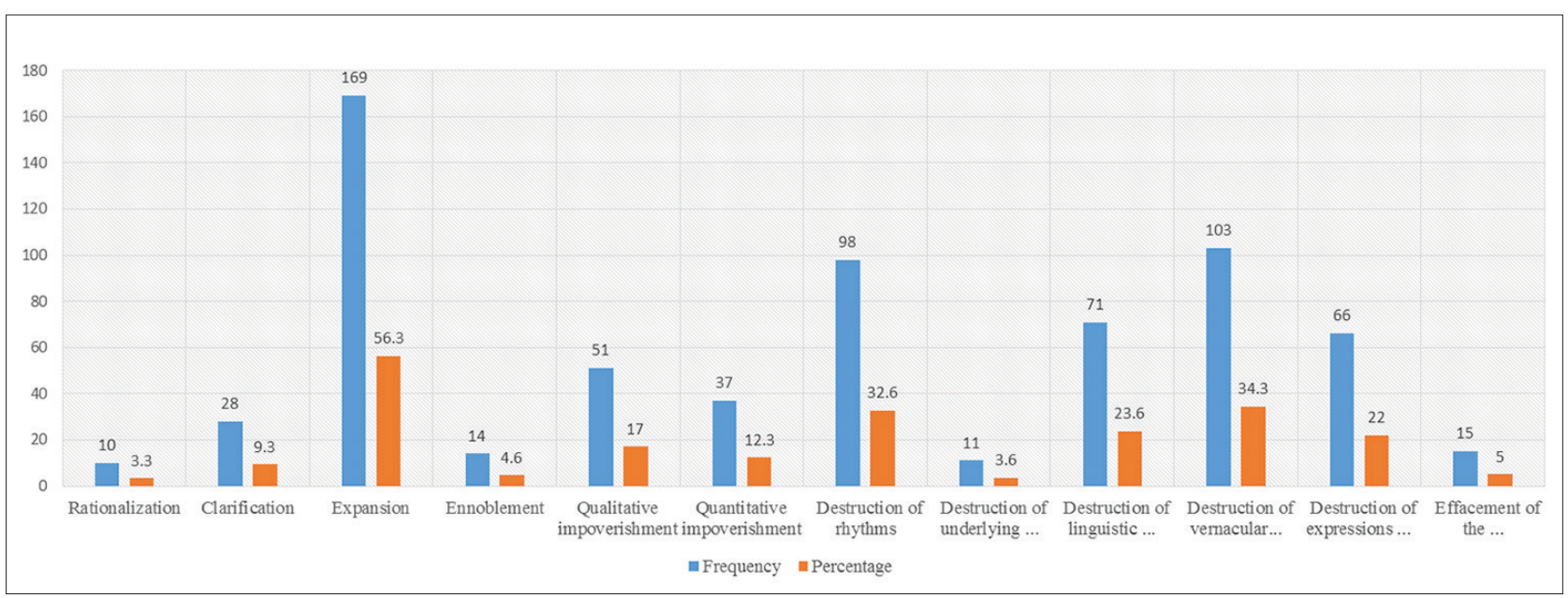

Figure 1. The frequency and percentage of the twelve deformation tendencies

was one of the most frequent deformation tendencies in their study. Another contradiction is related to the frequency of "the destruction of vernacular networks". While previously conducted studies did not report any instance of this item, in the present study it was the second most frequent deformation tendency. The existing contradictions between the two studies could be attributed to the nature and the genres across the two studies. For instance, since Hardy has used vernacular language very often in his novel, the translator is forced to destroy the vernacular networks more than poetry without vernaculars. Moreover, since the genre of corpuses in both studies was literary, we naturally expect more rhythmic language than non-literary texts. This point could be explained as a partial similarity between the findings of the two studies.

\section{CONCLUSION}

The main objective of the present research was to investigate the frequency of deforming tendencies in the translation of Hardy's Tess of the d'Urbervilles under Berman's model. Moreover, the study was set out to find out how words could experience changes from the source language (English) to fit the target language (Persian) by adopting deforming tendencies. The analyses of the data revealed that while the translation suffered from lexical mismatches, the translation mainly suffered from destruction of rhythms, and destruction of vernacular networks. It also appears that Berman offers a model which is too severe on keeping the form and syntax of the source text in the Persian translation of Hardy's Tess of the d'Urbervilles. By conducting the current study, it could be concluded that the translation has in one way or another maintained the genre, cultural and social stance of the author. It should be considered that cultural terms are deeply grounded in their cultures and oftentimes have a long history. Then, they are part of the identity of the source culture which should be faithfully represented in the translation. Since a translation should read as a translation, it cannot replace the original. The current study contributes to the study of translation theory as a globally informed and locally defined sociocultural and linguistic activity. As an area of research, the intersection of the ideologies of culture, and translation and the ways in which their changing relations to one another shape translation practices and theory hold great promise for the future. Moreover, to reinforce the importance of shifting from a linguistic-oriented translation approach to a cultural oriented one during the translation of different cultural element in English literary works, there are a number of general recommendations literary translators should take into consideration when dealing with cultural elements.

\section{REFERENCES}

Almasaeid, A., A. (2013). Some cultural and linguistic issues involved in translating the theme of love from Arabic into English in the Seven Odes translated by Frank Johnson. Education and practice, 4(3), 193-203.

Ary, D., Jacobs, L. C., Sorensen, C., \& Walker, D. A. (2014). Introduction to research in education (9 th ed.). USA: Wadsworth, Cengage Learning.

Berman, A. (1995). The Experience of the Foreign: Culture and Translation in Romantic Germany. Albany: State University of New York Press.

Berman, A. (2000). Translation and the trials of the foreignll, in: Lawrence Venuti (ed.), The Translation Studies Reader, pp284-297. London: Routledge.

Catford, J. C. (1965). A Linguistic Theory of Translation. London: Oxford University Press.

Dastjerdi, H., Hakimshafaaii, H., \& Jannesaari, Z. (2008). Translation of poetry: practical model for translation analysis and assessment of poetic discourse. Journal of Universal Language, 9(1), 7- 40.

Hariyanto, S. (2003). Problems in translating poetry. Retrieved from http://www.translation directory.com.

Jafari, Z., Kariminia, A. (2015). A Survey of Poetry Translation According to Antoine Berman's 1985. Text Deformation System: A Case Study of English Translation of Book II of Mathnavi Manavi. Journal of Applied Linguistics and Language Research, 2(2), 54-65.

Magvily, J. K., \& Thomas, E. (2009). A first qualitative project: Qualitative descriptive design for novice researchers. Journal for Specialists in Pediatric Nursing, 14(4), 298-300. 
Munday, J. (2016). Introducing Translation Studies: Theories and Applications (4 th ed.). New York: Routledge.

Murtisari, E. T. (2016). Explicitation in Translation Studies: The journey of an elusive concept, 8 (2), 45-60.

Nevalainen, S. (2004). Colloquialisms in Translated Text: Double Illusion? Across Languages and Cultures 5 , 67-88.

Newmark, P. (2001). A textbook of translation. Shanghai: Shanghai Foreign Language Education Press.

Nida, E. A. (2004). Toward a science of translating. USA: Brill Publication.

Niknasab, L., \& Pishbin, E. (2011). Translation and Interpretation 5(1), 1-6.

Pavlušová, I. (2014). Reverse naturalization in translation of a clockwork orange by A. Burgness. Journal of Translation and Interpretation, 6(1), 24-48.
Sharifabad, E. D., Yaqubi, M., \& Mahadi, T. S. T. (2013). The application of domestication and foreignization translation strategies in English- Persian translations of news phrasal verbs. Theory and Practice in Language Studies, 3(1), 94-99.

Simon, S. (2006). Translating montreal: Episodes in the life of a divided city. London: McGill-Queen's University Press.

Tezcan, T. (2015). Applicability of translation criticism approaches to different text types. Unpublished master thesis. Ankara: Hacettepe university graduate school of social sciences.

Venuti, L. (1995). The Translator's invisibility: A history of translation. New York: Routledge.

Venuti, L. (2012). The translation studies reader (3 th ed.). New York: Routledge. 